\title{
Aile Hekimlerinin Çalışma Şartlarının Değerlendirilmesi: Niteliksel Bir Araştırma Aile Hekimlerinin Çalışma Şartları
}

\author{
Evaluation Of Primary Care Physicians' Working Conditions: A Qualitative Research \\ Primary Care Physicians' Working Conditions
}

\author{
Erkut Etçioğlu ${ }^{1}$, Abdülkadir Aydın², Hasan Çetin Ekerbiçer ${ }^{3}$, Feride Özen ${ }^{4}$, \\ Muhammet Raşit Aydın' ${ }^{5}$, Elif Köse ${ }^{3}$, Gürkan Muratdağı ${ }^{6}$ \\ ${ }^{1}$ Osmaneli M.S.Ç Devlet Hastanesi, Aile Hekimliği Kliniği, Bilecik, Türkiye \\ ${ }^{2}$ Sakarya Ĕ̆itim ve Araştırma Hastanesi, Aile Hekimliği Kliniği, Sakarya, Türkiye \\ ${ }^{3}$ Sakarya Üniversitesi Tip Fakültesi, Halk Sağlığı Anabilim Dalı, Sakarya, Türkiye \\ ${ }^{4}$ Derince İlçe Sağllk Müdürlüğü, Aile Hekimliği Kliniği, Kocaeli, Türkiye \\ ${ }^{5}$ Sapanca İlçe Devlet Hastanesi, Aile Hekimliği Kliniği, Sakarya, Türkiye \\ ${ }^{6}$ Bahçelievler Aile Sağlı̆̆ı Merkezi, Sakarya, Türkiye \\ Yazıșma Adresi / Correspondence: \\ Erkut Etçioğlu \\ Osmaneli M.S.Ç. Devlet Hastanesi, Aile Hekimliği Kliniği, Osmaneli, Bilecik \\ T: +905535747837 E-mail : erkutetcioglu@gmail.com \\ Geliş Tarihi / Received : 09.03.2021 Kabul Tarihi/Accepte: 04.12.2021
}

Orcid :

Erkut Etçioğlu https://orcid.org/0000-0002-8117-7929

Abdülkadir Aydin https://orcid.org/0000-0003-0663-586X

Hasan Çetin Ekerbiçer https://orcid.org/0000-0003-0064-3893

Feride Özen https://orcid.org/0000-0003-0009-4433
Muhammet Raşit Aydın https://orcid.org/0000-0002-4202-0099 Elif Köse https://orcid.org/0000-0002-2232-4538

Gürkan Muratdağı https://orcid.org/0000-0002-9629-3973

( Sakarya Tip Dergisi / Sakarya Med J 2021, 11(4):757-764 ) DOI: 10.31832/smj.893432

\footnotetext{
Abstract

Introduction This study aimed to explore the working conditions of family physicians and to evaluate problems related to these conditions.

Materials A qualitative descriptive study design involving individual face-to-face in-depth interviews was used. Forty face-to-face interviews were conducted with family physicians

and Methods in Sakarya province. With the permission of the participants, audio recording was taken in all interviews except one, transcribed verbatim and checked. Thematic approach was used to analyze the data. Data was collected until data were saturated.

Results The data obtained from interviews with family physicians were evaluated under two main themes as "Problems in Working Conditions" and "Expected Improvements in Working Conditions". Family physicians participating in our research which evaluated the high number of registered population per family medicine unit, physical insufficiencies in working environments, financial problems, uncertainty in the job description of family physicians, and safety problems in Family Health Centers as the leading problems in working conditions. They offered solutions as to rapidly increasing the number of existing family physicians, making the appointment system mandatory, introducing new standards to the physical conditions of Family Health Centers, clarifying the job descriptions of family physicians, transferring financial responsibilities to higher authorities, and introducing deterrent sanctions against violence.

Conclusion The number of family physicians should be increased, their job descriptions should be clear so as not to cause role ambiguity and role conflict, their participation in decisions should be ensured, and physical conditions should be optimized.

Keywords Family medicine; primary healthcare; working conditions; qualitative research
}

Amaç Bu çalıs̆mada aile hekimlerinin çalışma koşullarının araştırılması ve bu koşullarla ilgili sorunların değerlendirilmesi amaçlanmıştır.

Yöntem ve Bireysel yüz yüze derinlemesine görüşmeleri içeren nitel tanımlayııı bir çalıșma tasarımı kullanılmıștr. Katıllmcıların izni ile biri hariç tüm görüșmelerde ses kaydı alınmış, kelimesi kelimesi-

Gereçler ne yazıya dökülmüs ve kontrol edilmistir. Verileri analiz etmek için tematik yaklașım kullanılmısstr. Veriler doygun hale gelene kadar yeterli sayıda aile hekiminden toplanmıștır.

Bulgular Aile hekimleri ile yapıllan mülakatlardan elde edilen veriler “Çalışma Șartlarındaki Problemler" ve "Çalı̦ma Șartlarında Beklenen L̀ileștirmeler" olarak iki ana tema altında değerlendirilmiștir. Araștırmamıza katılan aile hekimleri; aile hekimlï̆i birimi bașına düșen kayıtlı nüfusun fazla olmasıı, çalıșma ortamlarının fiziksel yetersizliklerinin olmasını, maddi problemlerin yașanmasını, aile hekiminin görev tanımında belirsizlikler olmasını ve Aile Sağllğı Merkezlerindeki güvenlik problemi olmasını calısma sartlarındaki önde gelen problemler olarak değerlendirmişlerdi. Mevcut aile hekimi sayısının hızla arttırılmasını, randevu sisteminin zorunlu hale getirilmesini, Aile Sağ̆lğı Merkezlerinin fiziki șartlarına yeni standartlar getirilmesini, aile hekimlerinin görev tanımlarının netleștirilmesini, mali sorumlulukların üst makamlara devredilmesini ve șiddete karşı caydırıcı yaptırımların getirilmesini çözüm önerileri olarak sunmuslardir.

Sonuç Aile hekimlerinin sayısı arttırılmal, görev tanımları rol belirsizliği ve rol çatısmasına yol açmayacak sekilde net olmal, kararlara katılımları sağlanmal, fiziki șartlar en uygun seviyeye getirilmelidir. 


\section{GIIRIŞ}

Birinci basamak sağlık kuruluşları ve aile hekimleri, sağlık hizmetinin ilk başvuru noktasıdır. Kişileri karşılama, problemlerini ve isteklerini dinleme, çözüm önerileri sunma ya da farklı basamaklara yönlendirmek gibi birçok fonksiyona sahiptir. Dünya Aile Hekimleri Birliği (WONCA) 2002 yılında yaptığı tanımlamada birinci basamağın, toplumun sağlık gereksinimlerinin karşılanmasında koordinatörlük görevi yaptığını ve tüm disiplin hizmetlerini belirli bir ölçüde kapsadığını belirtmiştir. ${ }^{1}$

Aile hekimine olan ihtiyaç Francis Peabody tarafından ilk kez 1923 yılında gündeme getirilmiş ve tıp bilimlerinde oluşan aşırı uzmanlaşmanın sonucu olarak bazı hastaların ortada kaldığını, bu nedenle kapsamlı ve bireysel sağlık hizmeti veren bir uzmanlık dalının gerekliliğine dikkat çekmiştir. ${ }^{2}$ Dünya Sağlık Örgütü (DSÖ) ise 1978 yılında yayınladığı Alma-Ata bildirgesinde birinci basamağın, sağlık hizmetlerinin örgütlenmesinde merkezi konumda olduğunu belirtmiştir. ${ }^{3}$

Türkiye Cumhuriyeti; 2002 yılında açıkladığı 'Acil Eylem Planı' içerisinde 'Herkese Sağlık' başlığı altında temel prensipleri belirlemiş ve uygulama için bir takvim oluşturmuştur. Bu doğrultuda Sağlık Bakanlığı, 2003 yılında "Sağlıkta Dönüşüm Programı”nı (SDP) uygulamaya koymuştur. ${ }^{4}$ SDP'nin temelini oluşturan Aile Hekimliği Uygulaması (AHU) ile, toplumun sağlık düzeyinin yükseltilmesi, ülke kaynaklarını uygun şekilde kullanarak daha fazla hizmetin sağlanması ve hakkaniyet ilkesi doğrultusunda toplumun sağlık hizmetlerine ihtiyaçları ölçüsünde ulaşmalarının gerek kırsal gerek kentsel bölgelerde, gerekse doğu ve batı bölgeleri arasında sağlık hizmetlerine erişim ve sağlık göstergeleri ile ilgili farklılıkların azaltılması amaçlanmıştır. $\mathrm{Bu}$ amaçlara erişebilmek için birinci basamak sağlık hizmetlerinin çağdaş bir yaklaşımla düzenlenip yaygınlaştırılması ve toplum bireyleri tarafindan tercih edilebilir şekilde sunulması gerektiği belirtilmiştir. ${ }^{5}$

Aile Hekimliği Pilot Uygulamasına 15.09.2005 tarihinde
Düzce ilinde başlanmıştır. 2010 yılı itibariyle tüm ülkede aile hekimliği sistemine geçilmiştir. Günümüzde 81 ilde birinci basamak sağlık hizmetleri aile hekimleri tarafından verilmektedir. $^{6}$

Bu çalışmada; aile hekimleri ile görüşmeler yapılarak, birinci basamak sağlık hizmeti veren aile hekimlerinin çalışma şartları ile ilgili değerlendirmeleri ve bu şartlar ile alakalı sorun yaşayıp yaşamadıkları, yaşadılarsa bu sorunlara yönelik bekledikleri iyileştirmelerin ve katılımcıların aile hekimliği uygulamalarının geliştirilmesine yönelik fikirlerinin değerlendirilmesi amaçlanmıştır.

\section{GEREÇ ve YÖNTEMLER}

Araştırma tasarımı: Bu çalışmada; Colaizzi'nin fenomenolojik yöntemi, aile hekimlerinin çalışma koşullarını niteliksel olarak analiz etmek ve bu koşullarla ilgili sorunları değerlendirmek için kullanılmıştır. Colaizzi’nin fenomenolojik yöntemi, katılımcıların deneyim ve duygularına odaklanmaktadır. Araştırma konularında bireysel özellikler yerine paylaşılan kalıplar bulur.

\section{Çalışma konuları}

Amaçlı bir örnekleme yöntemi kullanarak Sakarya ilinde çalışan 40 (28 erkek, 12 kadın) aile hekimini seçilmiştir. Dahil edilme kriterleri aile hekimliği yapıyor olmak idi. Aile hekimleri ile veriler doygun hale gelene ve yeni konu oluşturulmayana kadar görüşülerek gerekli yanıt sayısı belirlenmiştir.

Görüşme özeti: Görüşmede kullanılacak yarı yapıland1rılmış anket formu; ilgili literatür incelendikten sonra uzman görüşleri alınarak ön testler yapılarak hazırlanmıştır. Katılımcıların yaşı, cinsiyeti, medeni durumu, iş tecrübesi yılı, günlük hasta sayısı, görüşme öncesi birime kayıtlı kişi sayısı görüşmenin başlangıcında elde edildi. Katılımcılara yöneltilen ana mülakat soruları şunlardır:

1. Mevcut çalışma koşullarınızı nasıl değerlendiriyorsunuz? Çalışma koşullarınızla ilgili temel sorunlar nelerdir? 
2. Aile hekimliği pratiğini gelecekte daha verimli hale getirmek için çalışma koşullarınızda ne gibi iyileştirmeler yapılması gerektiğini düşünüyorsunuz?

3. Aile hekimliği uygulamasını tasarlıyor olsaydınız, mevcut uygulamadan farklı ne tür bir sistem tasarlardinız?

\section{Veri toplama}

Araştırmanın amacı ve önemi önceden katılımcıya anlatılmış ve uygun bir görüşme saati planlanmıştır. Görüşmeler sessiz bir şekilde ayrı bir odada kesintisiz olarak gerçekleştirilmiştir. Araştırmacılar, verilerin doğruluğunu artırmak ve önyargıdan kaçınmak için koşulsuz kabul, aktif dinleme ve açıklama gibi teknikleri kullandılar. Katılımcıların izni ile biri hariç tüm görüşmelerde ses kaydı alınmıştır. Ses kaydına izin vermeyen katılımcının ifadeleri görüşme sırasında bire bir not edilmiştir. Görüşmeler kişi başı 4050 dakika sürmüştür. Ses kayıtları, görüşmelerden sonraki 24 saat içinde araştırmacılar tarafından harfi harfine yazılmıştır ve doğruluk açısından görüşmeciler tarafından incelenmiştir. Veri analizi sırasında, tüm araştırmacılar sonuçlarla hemfikir oldular ve vurgulanan alıntıları seçmişlerdir.

$\mathrm{Bu}$ araştırmada "Aile Hekimlerinin Çalışma Şartlarının Değerlendirilmesi: Niteliksel Bir Araştırma” başlıklı uzmanlık tezi verileri baz alınmıştır.

Veri analizi: Her görüşmeden sonraki 24 saat içinde, kayıt Colaizzi’nin fenomenolojik analiz yöntemi ile yazıya dökülüp analiz edilmiştir. Üç araştırmacı, görüşme materyallerini bağımsız olarak gözden geçirip, anlamlı ifadeleri özetleyip çıkarmıştır ve mevcut temaları formüle etmişlerdir. Bir temanın içeriğiyle ilgili çelişkili görüşler araştırma grubu tarafından tartışılmış ve çözümlenmiştir.

\section{BULGULAR}

Katılımcıların \%70'i ( $\mathrm{n}=28)$ erkek, \%30’u ( $=12)$ kadındır. Yaş ortancası 41 (35-49) yıldır. Araştırmaya katılan aile hekimlerinin aile hekimliği görev süresi ortancası 10 (4,75-
10) yıl iken, aile hekimliği birimine kayıtlı nüfus sayısı ortancası 3500 (3257-3734,75) kişidir. (Tablo-1)

\begin{tabular}{|c|c|c|c|c|}
\hline \multicolumn{4}{|c|}{ Tablo-1: Katılımcıların Karakteristiği } & \multirow[b]{2}{*}{$\%$} \\
\hline & & $\begin{array}{c}\text { Ortanca } \\
\text { (1. ve 3. Çeyrek) }\end{array}$ & $\mathrm{n}$ & \\
\hline Yaş (yıl) & & $41(35-49)$ & & \\
\hline \multirow{2}{*}{ Cinsiyet } & Erkek & & 28 & 70 \\
\hline & Kadın & & 12 & 30 \\
\hline \multicolumn{2}{|c|}{ Aile Hekimliği deneyimi (yıl) } & $10(4,75-10)$ & & \\
\hline \multicolumn{2}{|c|}{ Kayıtlı nüfus sayısı } & $3500(3257-3734,75)$ & & \\
\hline
\end{tabular}

Aile hekimleri ile yapılan mülakatlardan elde edilen veriler "Çalışma Şartlarındaki Problemler” ve "Çalışma Şartlarında Beklenen İyileştirmeler” olarak iki ana tema altında değerlendirilmiştir. (Tablo-2)

\begin{tabular}{|l|l|}
\hline \multicolumn{2}{|l|}{ Tablo-2: Tema ve Kategoriler } \\
\hline \multicolumn{2}{|l|}{ Çalışma Şartlarındaki Problemler } \\
\hline & Kayıtlı nüfus sayısı fazlalı̆̆ı \\
\hline & Çalışma ortamının fiziksel yetersizlikleri \\
\hline & Maddi problemler \\
\hline & Görev tanımının belirsizliği \\
\hline & Güvenlik problemi \\
\hline Çözüm Önerileri \\
\hline & Aile hekimi sayısının arttırılması \\
\hline & Randevu sisteminin getirilmesi \\
\hline & Fiziksel imkânların standardize edilmesi \\
\hline & Aile hekimlerinin görev tanımının netleştirilmesi \\
\hline & Mali sorumlulukların devredilmesi \\
\hline & Şiddete yaptırımın arttırılması \\
\hline
\end{tabular}

\section{Aile Hekimlerinin Çalışma Şartlarındaki Problemler}

Yapılan görüşmelerde aile hekimlerinin çalışma şartlarındaki problemlerin başında birimlerine kayıtlı nüfus sayılarının yüksekliğinin geldiği görülmüştür. Verilen sağlık hizmetlerinin sorunsuz tesisinin önündeki en büyük engel olarak görülen birim başına düşen kayıtlı kişi sayısının fazlalığı katılımcıların büyük çoğunluğunun aklına gelen ilk problem olarak karşımıza çıkmıştır. 
“...hekim başına düşen nüfus sayısı oldukça fazla. Şu an benim kayıtlı nüfusum 3900, mevcut mesai saatlerinde bu kadar hastaya sağlık hizmeti vermem imkansız, kaldı ki koruyucu sağlık hizmeti, bilgilendirme konularına ayıracak vakit bile kalmiyor."

“...hasta yoğunluğu çok fazla... aile hekimliğinin tanımında olan koruyucu sağlık hizmetini neredeyse hiç yapamıyoruz. Çok fazla poliklinik başvurusu oluyor. Hastalarımıza gerekli zamanı ayıramıyoruz."

“...hasta yoğunluğu çok fazla ve randevu sistemine hala geçilemedi. Aile hekimliğinin tanımında olan koruyucu sağlık hizmetini neredeyse hiç yapamıyoruz. Çok fazla poliklinik başvurusu oluyor. Hastalarımıza gerekli zamanı ayıramiyoruz."

“...yıldan yıla çoğu uygulama performans olarak mevzuata eklendi. Ama bu uygulamalar ciddi vakit harcanması gereken uygulamalardır fakat mevcut nüfus sayısında bunları yapmak imkansızdır. Çalışma süremiz içerisinde bunları yapmak son derece zordur. Kağıt üzerinde güzel ama realitede yapılması imkansızdır.”

Aile hekimleri, görev yaptıkları Aile Sağlı̆̆ı Merkezlerinin fiziki şartlarından kaynaklanan olumsuzlukları bir diğer önemli problem olarak belirtmişlerdir. Katılımcıların hiçbiri görev yaptıkları yerleşkenin fiziki şartlarından memnun olduğunu ifade etmemiştir. Aile Sağlığı Merkezleri için belirlenmiş standartlara uygun görünse de binaların mimari özelliklerinin dahi ciddi problemlere neden oldugunu belirtmişlerdir.

“...binamız depremden önce kalma bir bina, binanın temeli su bile alıyor, etrafı çatlak bir şekilde yağan yağmurun hepsi binanın temeline gidiyor, elektrik sistemimiz çok eski, çok sıkıntı yaşıyoruz"

"hasta bekleme alanı için yeterli alanımız yok, lavabo olmayan odalarımız var, bina eski ve burada çalışmamız uygun görülüyor. Başka bir binaya taşınmak için elimizi cebimize atmamız gerekiyor."

Katılımcı aile hekimleri maddi konularda gün geçtikçe kayba uğradıklarını, yıllar içerisinde aldıkları maaşların güncel piyasa şartlarına göre azaldığını, cari giderlerin ise çok arttığını belirtmişlerdir. Bu gelir gider dengesizliğinin motivasyon kaybına da sebep olduğunu ifade etmişlerdir.

“...ödeme noktasında çok geriye gittik. Maddi kazancımızda çok ciddi bir azalma var yıldan yıla. Hem personel çalıştırıyoruz, onların maaşları artıyor ama bizim cari gider ödemelerimiz aynı oranda artmadı"

“...en başta iyileştirilmesi gereken şey; yapılan işin karş1lığının verilmesidir. Hem maddi anlamda hem manevi anlamda. Maaşlarımız yıllar içerisinde eridi, iyileştirilmesi gerekir."

Araştırmaya katılan aile hekimleri; görev tanımlarının net olmadığını, sağlık sistemi işleyişinde yeni uygulamaların eksiklerinin aile hekimleri ile kapatılmaya çalışıldığını, bunun da rutin işlerine gereksiz yük getirdiğini belirtmişlerdir. Özellikle aile hekimlerinin işleyişteki açıkların kapatılmasında kullanıldığından yakınmışlardır.

“...aile hekimliğinin görev tanımının açık bir şekilde yazılması lazımdır. Görev tanımının içine nelerin dahil nelerin dahil olmadığının açık bir şekilde yazılması lazım.”

"Kimi zaman hekimlikle alakalı olmayan işlerin bir anda aile hekimlerine yıkıldığını görüyoruz. Görev tanımı net olmayınca ne iş artsa bize yansıması oluyor.”

"Görev tanımımız belli değil. Güya belli ama çok esnek bence. Yeni bir iş çıkıyor. Kim yapsın bunu? Aile hekimleri yapar deniyor."

Güvenlik konusunda aile hekimleri diğer sağlık tesislerinde çalışanlar kadar güvende olmadıklarını, Aile Sağlığı 
Merkezlerinde herhangi bir güvenlik olmadığını, yalnızca yaşanabilecek olumsuzluklar sonrası değerlendirilebilecek uygulamalar olduğunu ifade etmişlerdir.

“...güvenlik görevlisi yok. Bizi her şekilde darp edebilir, öldürebilir ve elini kolunu sallayarak buradan çıkabilir. $\mathrm{Ne}$ girişte bir X-Ray cihazı var ne de sesimizi duyacak bir güvenlik görevlisi”

"Bence en güvensiz ortamda çalışan sağlık çalışanları bizleriz. Başımıza bir iş gelse önleyecek durum yok. Sadece başına iş geldi mi şikayet mekanizması var.”

\section{Aile Hekimlerinin Çalışma Şartlarının İyileştirilmesi İle İlgili Çözüm Önerileri}

Aile hekimlerinin ön plandaki yakınması olan kayıtlı nüfusun fazlalığının önüne geçilmesi için aile hekimi sayısının hızla arttırılması gerekliliğini vurgulamışlardır. Bunun yanında kayıtlı nüfusta azalma sağlanamayacak ise randevu sisteminin getirilmesi ve birinci basamakta randevusuz hasta bakılmasının engellenmesi gerektiğini savunmuşlardir.

“...hasta sayısının 2000’i geçmemesi gerektiğini düşünüyorum. Her aile hekimine maksimum 2000 kişilik kontenjan olacak bir düzenleme gerekli.”

“...bu sağlanamazsa randevulu bir sistem olmalı. Her vatandaşın ulaşabileceği bir randevu sistemi olmalıdır. Böylece birinci basamağın daha efektif olacağı düşüncesindeyim."

Katılımcılar Aile Sağlığı Merkezlerinin fiziki şartlarındaki olumsuzlukların ancak belli yeni standartlar getirilerek çözülebileceğini, mevcut standartların yetersiz olduğunu savunmuşlardır.

"Bence gelişigüzel her yerde farklı farklı binalarda Aile Sağlığı Merkezi olmaz. Bir proje çizilmeli ve memleketin her yerinde Aile Sağlığı Merkezleri aynı standarda ve aynı fiziki şartlara sahip olmalı.”

Katılımcıların en göze çarpan problemlerinden biri de aile hekimlerinin görev tanımlarının net olmamasıydı. Bunun için aile hekimliği akademisyenlerinin, sahada aktif çalışan aile hekimlerinin ve sağlık politikası yürütücülerinin bir çatı altında buluşup, aile hekimin görev tanımlarının netleştirilebilmesi için çalışmalar yapması gerektiğini savunmuşlardır.

"Bir aile hekiminin kendi görev ve sorumluluklarını bilmesi gerekiyor. Bunu kanunla ortaya koymak gerektiği düşüncesindeyim”

“Türkiye'de 30.000 üstünde aile hekimi var. Bu kadar hekimi ilgilendiren bir mevzuda ciddi bir görev tanımı gereklidir. Her şeye biz görevlendiriliyoruz. Görev tanımımız olursa neyi nasıl yapacağımız net olur."

Aile hekimleri gelir gider dengesizliğine vurgu yaparak; Aile Sağlığı Merkezlerinin bir özel işletme gibi görülmesinden vazgeçilip, Aile Sağlı̆̆ı Merkezlerinin giderlerinin karşılanmasının aile hekimlerinden alınıp üst mercilere devredilmesi gerektiğini ve aile hekimlerinin olağan iş yüküne bir de mali uğraşların eklenmemesi gerektiğini savunmuşlardır.

“Aile hekimi parayla pulla uğraşmamalı. ASM’ler küçük işletmeler gibi. Aile hekimleri de ortaklar. Herşeyimizi biz karşılıyoruz. Devlet giderler için ödeme yapıyor tabiki ama bunun sadece maddi yönü yok. Büyük bir uğraş ve kafa meşguliyeti. Cari gider ödemesin devlet ama ASM'sine de baksin."

"Bu gider mevzusu büyük problem. Devlet bu yükü bizim sırtımızdan almalı. İş yükümüz zaten fazla bir de mali işlerle uğraşıyoruz."

Katılımcılar Aile Sağlığı Merkezlerinde güven kaygılarının olduğunu belirtmişler ancak bu güvensizlik durumunun 
alınacak önlemlerle mümkün olmayacağını düşündüklerini ifade etmişlerdir. Çözüm yolu olarak cezai yaptırımların artırılması gerektiğini düşündüklerini belirtmişlerdir.

“... ancak güvenlik görevlisi bulundurma vs. gibi çözümlerle aşılamaz. Şiddet en ağır şekilde cezalandırılmalı. Caydırıcılığı olmalı.

"bana kalırsa tek çözümü ağır cezalar getirilmesi. Bu sadece bizim problemimiz değil tüm sağlık çalışanlarının problemi aslında. Ama bizim riskimiz daha fazla sanki.”

\section{TARTIŞMA}

Araştırmamıza katılan aile hekimleri; aile hekimliği birimi başına düşen kayıtlı nüfusun fazla olmasını, çalışma ortamlarında fiziksel yetersizliklerinin olmasını, maddi problemlerin yaşanmasını, aile hekiminin görev tanımında belirsizlikler olmasını ve Aile Sağlığı Merkezlerinde güvenlik problemi olmasını çalışma şartlarındaki önde gelen problemler olarak değerlendirmişlerdir. Mevcut aile hekimi sayısının hızla arttırılmasını, randevu sisteminin zorunlu halde getirilmesini, Aile Sağlığ 1 Merkezlerinin fiziki şartlarına yeni standartlar getirilmesini, aile hekimlerinin görev tanımlarının netleştirilmesini, mali sorumlulukların üst makamlara devredilmesini ve şiddete karşı caydırıcı yaptırımların getirilmesini çözüm önerileri olarak sunmuşlardır.

Birinci basamak sağlık hizmetlerinin güçlü ve etkin olmaS1, çalışan hekimlerin çalışma şartlarının en uygun düzeyde olmasına bağlıdır. Bu durum toplum sağlığının gelişmesi açısından büyük önem taşımaktadır. ${ }^{7}$

Ülkemizde aile hekimlerinin mesleki sorunlarına yönelik yapılan bir araştırmanın sonuçlarında aile hekimliğinin temel probleminin herkes tarafından kabul edilmiş bir tanımının ülkemizde olmaması olduğu belirtilmiştir. ${ }^{8}$ Araştırmamızda da benzer şekilde aile hekimliği tanımının olmadığı adeta bir joker eleman olarak kullanıldığını belirten katılımcılar olmuştur. Araştırmamızda katılımcı- ların çoğu sistemde yapılması gereken iyileştirmeler içinde öncelikle aile hekimliği tanımının tam olarak yapılması ve yasal zemininin sağlam olması gerektiğini belirtmişlerdir. Katılımcılar araştırmamızda temel problem olarak gördükleri, görev tanımlarının belirsizliği, rol belirsizliği ve rol çatışması konularının tartışmaya açık olmayacak şekilde planlanması gerektiğini belirtmişlerdir.

Algın ve arkadaşları yaptıkları araştırma sonuçlarında aile hekimlerinin çalışma ortamı ile ilgili sorunlar ile ilgili olarak; çalışılan ortamın fiziki durumu (ısıtma, aydınlatma vb. gibi), çalışma ortamının teknik donanım yeterliliğinin genel olarak orta düzeyde olduğunun görüldüğünü belirtmişlerdir. ${ }^{8}$ Bizim araştırmamızda da katılımcı aile hekimlerinin büyük bir bölümü çalışılan ortamdaki yetersizliklerin çalışma şartlarındaki en büyük sorunlardan biri olduğunu vurgulamışlardır. Bu yetersizliklerin de ideal sağlık hizmet sunumu için bir engel teşkil ettiğini belirtmişlerdir. Geliştirilmesine yönelik fikirleri içerisinde ise; bina ve donanım konusunu en başa koymuşlardır.

Ülkemizde yapılan bir çalışmada sahada çalışan aile hekimleri maaş ve ek gelirlerinin iyileştirilmesi gerektiği belirtilmiştir. ${ }^{9}$ Bizim araştırmamızda aldığı ücreti yeterli bulan hiçbir katılımcı olmayıp her geçen gün de bu ücretlerin eridiği belirtilmiştir. Belirtilen bu durumlardan aile hekimlerinin ücret konusundaki sorunlarının yıllardır devam eden kronik bir sorun olduğu çıkarımı yapılabilir. Araştırmamıza katılan aile hekimlerinin çoğunluğu iyileştirilmesi gereken konularda bu konunun üzerinde durmuşlardır.

Literatürde; hekim başına düşen hasta sayısındaki artışın hekim sayısı artışına oranla fazla olduğu belirtilmiştir. Sağlık hizmet sunum kalitesinden taviz verilmek durumunda kalındığına vurgu yapılmıştır. Sahada çalışan aile hekimi başına düşen nüfus sayısının 3500-4000'lerden 2000- 3000'lere düşmesi gerektiği ve bunun sonucu olarak da aile hekimlerinin her hastasına daha fazla zaman ayırabileceği belirtilmiştir., ${ }^{90}$ Bizim araştırmamızda katılımc1- 
lar birimlerine kayıtlı nüfus sayılarının çok fazla olduğunu yapılan poliklinik sayısının mesai saatine bölümünde elde edilen sürenin hastayı değerlendirmek için yetersiz bir süre olduğunu belirtmişlerdir. Bu kısa sürede hastayı değerlendirmek bile mümkün değilken aile hekimliği uygulamalarının temelinde olan ve görev tanımında yer alan koruyucu sağlık, eğitim ve bilgilendirme gibi hizmetleri gerçekleştirmenin de imkansız olan bir diğer konu oldugunu ve yapılacak iyileştirmelerin bu konularda olması gerektiğini de görüşlerinde belirtmişlerdir.

\section{SONUÇ}

Gelecek sağlık stratejileri için aile hekimliği sisteminin güçlü olması kaçınılmaz bir gerçektir. Hasta memnuniyeti için; etkin ve verimli sağlık sistemi için birinci basamak sağlık hizmetlerinin geliştirilmesi; birinci basamak hekimlerinin görüşlerinin planlamalar dahilinde olması ve çalışma şartlarının en uygun düzeye getirilmesi gereklidir.

Birinci basamak sağlık hizmetlerine gereken destek ve önem verilmelidir. Bir takım konularda seri düzenlemeler yapılması gerektiği kanaatindeyiz. Aile hekimlerinin sayısı arttırılmalı, görev tanımları rol belirsizliği ve rol çatışmasına yol açmayacak şekilde net olmalı, kararlara katılımları sağlanmal, fiziki şartlar en uygun seviyeye getirilmelidir.

\section{Etik Onay}

Bu araştırma için etik onayı Sakarya Üniversitesi Tip

Fakültesi Etik Kurulu'ndan alınmıştır. (Onay tarihi:

21.06.2019, Say1:E-8222) 
Sakarya Tip Dergisi2021;11(4):757-764

ETÇíOĞLU ve Ark., Aile Hekimlerinin Çalışma Şartlarının Değerlendirilmesi: Niteliksel Bir Araștırma

\section{References}

1. Europe W. The European definition of general practice/family medicine. WONCA Europe 2002;4-6,7-43.

2. T.C. Sağlık Bakanlığı Sakarya İl Sağlık Müdürlüğü. (2020) Erişim Tarihi:08.03.2021, erişim adresi: https://sakaryaism.saglik.gov.tr/TR-34675/dunyada-aile-hekimligi.html

3. Özcan F, Ünlüoğlu İ. Türkiye'de ve dünya'da aile hekimliği. Sendrom 1996;8(7):83-5.

4. Çavmak Ş, Çavmak D. Türkiye’de sağlı hizmetlerinin tarihsel gelişimi ve sağllkta dönüșüm programı. Sağlık Yönetimi Dergisi 2017;(1)1:48-57.

5. T.C. Halk Sağlı̆̆ı Genel Müdürlüğü. (2020) Erișim Tarihi: 08.03.2021, erișim adresi: https:// hsgm.saglik.gov.tr/tr/ailehekimligi/t\%C3\%BCrkiye-de-aile-hekimli\%C4\%9Fi.html
6. T.C. Halk Sağglğı Genel Müdürlü̆üü. (2020) Erişim Tarihi:08.03.2021, erişim adresi: http:// hsgm.saglik.gov.tr/tr/ailehekimligi/t\%C3\%BCrkiye-de-aile-hekimli\%C4\%9Fi.html

7. Aktaş EÖ, Çakır G. Aile hekimlerinin, aile hekimliği uygulaması hakkındaki görüşleri: Bir anket çalışmast. Ege Tip Dergisi 2012;51(1):21-29.

8. Algın K, Şahin İ, Top M. Türkiyedde aile hekimlerinin mesleki sorunları ve çözüm önerileri. Hacettepe Sağllk İdaresi Dergisi 2004;7(3) 249-75.

9. Ayhan Başer D, Kahveci冈 R, Koç M, Kasım İ, Șencan İ, Özkara A. Etkin sağlık sistemleri için güçlü birinci basamak. Ankara Med J 2015;15(1).

10. Akman M. Türkiye'de birinci basamağın gücü. Türk Aile Hek Derg 2014;18(2):70-78 